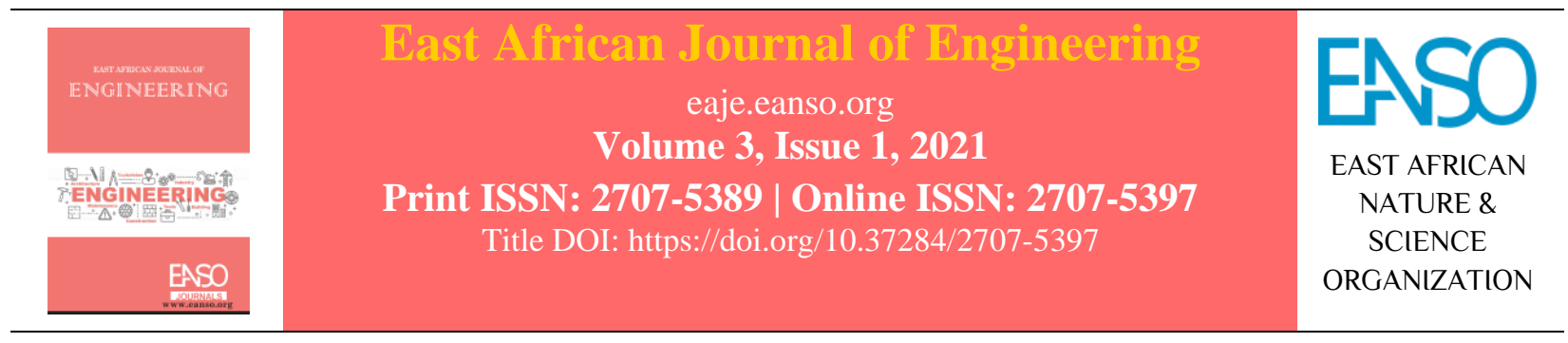

Original Article

\title{
Simulation of Green Building Materials Uses and its Environmental Impacts: Case of Jordan.
}

\author{
Abdalrahman Hammoudah Yousef Alhndawi, MSc ${ }^{l^{*}}$, Prof. Nur Ismarrubie Zahari, PhD ${ }^{l}$ \& Prof. Suraya \\ bt. Mohd Tahir, PhD ${ }^{l}$ \\ ${ }^{1}$ Department of Mechanical and Manufacturing Engineering, Faculty of Engineering, Universiti Putra Malaysia, 43400 Serdang, \\ Selangor, Malaysia, 21555. \\ * Author for Correspondence ORCID: 0000-0002-8856-5510; Email: sharaf12111995@yahoo.com.
}

Article DOI: https://doi.org/10.37284/eaje.3.1.410

\section{Publication Date: ABSTRACT}

14 September 2021 Construction is one of the most important factors affecting the environment such as global warming and carbon dioxide emissions. In

Keywords: addition, it represents $40 \%$ of the consumption of energy resources around the world. Jordan is one of the countries that suffer greatly from

Green Building, Construction Management, Green Building in Jordan,

ArchiCAD, Modelling, Simulation. this aspect. In this research, a simulation was conducted of a multi-use building located in a university in Jordan using the ArchiCAD program, which helps us to accurately determine the construction location and obtain the results of materials and strategies that were applied to the building. Thermal insulation materials were used to show the effectiveness of their impact on the temperature difference per unit of heat flux needed to sustain one unit of heat flux (R-value) for the building. Shading means were also applied to the building's glass facades that reduce heat loads and help the heating, ventilation, and air conditioning (HVAC) system inside the building. Finally, it was shown the difference in the environmental impact of a building that uses $100 \%$ solar energy and emits zero CO2 emissions. While a building that uses 50\% solar energy and 50\% oil energy emits a high amount of $\mathrm{CO} 2$. It becomes clear that the increasing use of green building tools helps greatly in facing the problems of the environment and the consumption of energy resources.

\section{APA CITATION}

Alhndawi, A. H. Y., Zahari, N. I., \& Tahir, S. M. (2021). Simulation of Green Building Materials Uses and its Environmental Impacts: Case of Jordan East African Journal of Engineering, 3(1), 79-98. https://doi.org/10.37284/eaje.3.1.410

\section{CHICAGO CITATION}

Alhndawi, Abdalrahman Hammoudah Yousef, Nur Ismarrubie Zahari, \& Suraya bt. Mohd Tahir. 2021. "Simulation of Green Building Materials Uses and its Environmental Impacts: Case of Jordan". East African Journal of Engineering 3 (1), 79-98. https://doi.org/10.37284/eaje.3.1.410.

79 | This work is licensed under a Creative Commons Attribution 4.0 International License. 


\section{HARVARD CITATION}

Alhndawi, A. H. Y., Zahari, N. I., and Tahir, S. M. (2021) "Simulation of Green Building Materials Uses and its Environmental Impacts: Case of Jordan”, East African Journal of Engineering, 3(1), pp. 79-98. doi: 10.37284/eaje.3.1.410.

\section{IEEE CITATION}

A. H. Y., Alhndawi., N. I. Zahari., \& Tahir, S. M. "Simulation of Green Building Materials Uses and its Environmental Impacts: Case of Jordan," EAJE, vol. 3, no. 1, pp. 79-98, Sep. 2021.

\section{MLA CITATION}

Alhndawi, Abdalrahman Hammoudah Yousef, Nur Ismarrubie Zahari, \& Suraya bt. Mohd Tahir. "Simulation of Green Building Materials Uses and its Environmental Impacts: Case of Jordan.” East African Journal of Engineering, Vol. 3, no. 1, Sep. 2021, pp. 79-98, doi:10.37284/eaje.3.1.410.

\section{INTRODUCTION}

\section{General Overview}

The world has recently become more focused on the environment and its concerns due to the increasing environmental risks that affect the entire world as a result of natural resource depletion and improper use. Thinking about future energy sources has become a concern for many countries, even most of them, especially in developing countries. Many of the modern political and economic conditions related to the environmental aspect have had a negative impact on this aspect, placing a greater burden on the shoulders of decision-makers and specialists in this field of the need to make additional efforts to find environmental solutions suitable for the current situation.

Building is one of the key factors affecting the environmental aspect, as it accounts for almost $40 \%$ of global energy consumption (Houser, 2009). Moreover, according to the United Nations Program, it is mainly responsible for carbon dioxide emissions that affect the climate and global warming, as well as other concerns associated with the consumption of natural resources such as wood and raw materials. It is also one of the sources of environmental pollution (Bhutt, 2017). China is considered one of the countries with the highest energy consumption in the world, where the construction industry occupies approximately 38\% of the total energy consumption there ( $\mathrm{Lu}$ et al., 2018).
These environmental dangers have a significant impact on the Middle East region. Jordan is regarded as one of the emerging countries that are falling behind in terms of implementing beneficial environmental steps. Jordan consumes around 33\% of the energy resources in construction. Construction accounted for around $41 \%$ of total electricity use (Barari, 2013), and it already faces a scarcity of natural resources. From this arose the significance of the notion of green building for the globe in general and, more specifically, for Jordan and developing countries like it. Green building is seen as the best approach for addressing environmental challenges, providing a comfortable atmosphere for the current generation, and preserving future generations' rights to natural resources and a good life.

Green construction, often known as sustainable building, has many distinct definitions for scholars and authorities. Kibert, for example, defines green building as a "facility that is designed and built with a strategy that helps to use natural resources properly and is consistent with sound environmental habits" (Kibert, 2016). Others have also defined a green building as "the construction of buildings using environmental processes that take into account the correct use of resources. Environmental project from the beginning of the project begins with determining the site, through construction and maintenance, and ending with demolition and dismantling" (WCED, 1987). It is worth noting that the concept of sustainability described in the socalled Bruntland report is the development that meets all of the demands of the current generation

80 This work is licensed under a Creative Commons Attribution 4.0 International License. 
without compromising the abundance of needs of future generations.

\section{Problem Statement}

Jordan's population is estimated at 10.726 million, and its land area is approximately $89,342 \mathrm{~km}^{2} .80 \%$ of Jordan's population lives in urban areas, further depleting natural resources to meet urban construction and development needs (Hassouneh et al., 2015). Jordan has suffered in the recent past from importing $95 \%$ of its energy from other countries. This situation improved a little after the establishment of power plants, but not enough to make the state self-sufficient in energy, or even close to it (Martinez et al., 2008).

The concept of building in Jordan lacks the use of green building strategies and tools that help reduce energy consumption in buildings, such as site selection, design, materials used, and recyclability (Alshorman et al., 2018). Jordan records high numbers of carbon dioxide emissions, estimated at 20 million tons, distributed over different sectors, including the construction sector (Dar-Mousa \& Makhamreh, 2019). As a result, Jordan faces serious environmental threats, which prompts it to impose laws and pledges that will fight environmental pollution.

\section{Aim and Objectives of Study}

Almost $90 \%$ of people's time is spent in indoor activities. Thus, construction is an essential aspect in influencing all aspects of people's livelihood. Because utilities are of such importance, the research aims to provide tools and means that will improve construction sustainability and take advantage of natural energy sources through this research. Therefore, the objectives of this research as follow:

- Determine the effect of thermal insulation and its efficiency on the building.
- Evaluate the effectiveness of shading means on the glass facades of the building.

- Analyse the environmental impact of the building by conducting a comparison between the different energy sources of the building.

\section{LITERATURE REVIEW}

The study of environmental causes and the attempt of human adaptation to natural energy sources and their usage in architecture is an ancient phenomenon. This adaptability changed throughout time. For example, we can observe the architecture and the use of natural resources such as bricks and natural stones in the construction of temples and carving mountains, as well as the use of wood in the construction of the dwellings of the working class. All the strategies that were followed in the construction style at this time help to adapt to the natural factors such as sunlight, wind strength and direction, temperature, and intensity of rain. Furthermore, we witness the adoption of several environmental solutions in the ancient Islamic civilization, such as windbreaks, the allocation of interior spaces for mosques, and shading strategies such as Mashrabyeh. The human attempt to adapt to his environment and the search for solutions with all developments is a prevalent phenomenon that we can see through the ages.

The urban study side has not been neglected in the modern era, but it has taken an environmentally unfriendly path, especially with the introduction of chemical and industrial building materials, nonrecyclable materials, and building methods that are not considered good for the environment, which began to negatively affect the environment. As a result, over the last few decades, officials and specialists in the field of construction, among others, have begun to seek environmental solutions that provide the same productivity outcomes while also preserving the state's and the world's environmental values. Scientists began to conduct studies and publish research papers clarifying the

81 This work is licensed under a Creative Commons Attribution 4.0 International License. 
concept of the green building convey it to officials. After several practices of green building strategies, officials and implementers found that this idea is bearing fruit. This concept began gradually to spread from the developed countries to the developing and somewhat industrially backward countries. The development of environmental knowledge in societies has shown a reflection on their way of life. A part of society has made it a priority in their lifestyle. Then studies and research began to be practically applied through building classification systems, which in turn analyse the facility's eligibility for the title green or sustainable building. Leadership in Energy and Environmental Design (LEED) and Building Research Establishment Environmental Assessment Method (BREEM) systems, as well as additional systems around the world.

\section{Green Building in the World}

The concept of green architecture first appeared around the beginning of the nineteenth century. Ceiling fans and floor air coolers from London's Crystal Palace in 1851 and Milan's Galleria Vittorio Emanuele 11 in 1877 were utilized (Gissen, 2010). Then, between 1903 and 1905, sun-shading windows were installed in the Flatiron Building and the New York Times Building. Retractable canopies such as those used on the Wainwright Building in New York in the 1930s and other environmental technologies that appeared at that time. Because of the environmental crises that began to emerge in the early 1970s, the notion of the green building began to spread at the turn of the twentieth century. Studies and research began to be conducted to find solutions to the energy crisis that was brewing at the time, particularly in the United States, Canada, and Western Europe. According to international research, emissions would dramatically increase by 2050, necessitating the urgent demand for green buildings.

The notion of the green building took a significant step forward in the second half of the 1990s
(Cedeño-Laurent et al., 2018). The United States of America, for example, was among the first in this sector. In 1977, it formed the Ministry of Energy to address and preserve energy use, as well as the Solar Energy Research Institute, which eventually changed its name to the National Renewable Energy Laboratory, and other establishments that are interested in environmental aspects. Engineering Systems International (ESI) examines the environmental indicators of countries based on an experimental basis. Finland, Norway, Uruguay, Iceland, and Sweden are the top five countries. They are those countries that possess a large number of natural resources and a low population (Tripathy et al., 2005). On top of these international environmental activities, Britain, America, and other countries launched assessment systems for green buildings.

\section{International Green Building System}

Many global assessment systems have been established by countries to help improve and monitor their environmental sustainability. Because the first system was formed in 1990, the American BREEM rating system is at the forefront of these systems. This system assigns a score (fair, good, very good, excellent) based on social, economic, and environmental factors. BREEAM is the largest green building certification facility (Gibberd, 2002). Countries then started working on establishing their systems such as German Sustainable Building Council (DGNB) (Millán et al., 2010), Green Star, Green Building Index and Jordanian Green Building Council (JGBG) systems in Germany, Australia, Malaysia, and Jordan, respectively. Finally, it is worth mentioning that the American LEED system, which is widely used throughout the world, began development in 1993 and released its first program 1.0 in 1998. All of these regulations are optional. And, while there may be some discrepancies between the systems, they all have one thing in common: they are built by environmental specialists who research and monitor everything that benefits 
this field and design new techniques that work in its favour (Matarneh, 2017).

\section{Green Building in Jordan}

As one of the developing countries in the Middle East, Jordan is one of the countries in which the green building concept has lagged despite an urgent need for it. The total population of nearly 10 million people is increasing rapidly, especially with the political situation in the surrounding countries and the resulting displacement to Jordan. The Jordanian Green Building Council (JGBC), which was established in October 2009 and launched in 2015 (Kaatz et al., 2006), allocated concepts to guide the national building towards the concept of the green building. The JGBC includes engineers and green building specialists who strive to develop green buildings in Jordan and the consolidation of this idea among the Jordanian people. The Dutch Embassy building in Jordan was the first building to achieve LEED Silver Certification for Green Building (Samy \& Barakat, 2019). In the last four years, the concept of the green building began to spread gradually among specialists, engineers, government agencies, and even individuals. Solar energy is one of those concepts that have spread strongly in Jordan and other energy sources.

\section{Solar Energy and Other Natural Sources in Jordan}

According to Eng. Ahmed Abu Sa'a, an official at the Ministry of Energy and Mineral Resources, Jordan enjoys 300 sunshine days every year. And the sun's rays in Ma'an Governorate's Al- Jafr region are among the highest in the world. The government's engagement in solar energy began with the establishment of the Ain Shams station in the Ma'an region in 2016, which is one of the largest solar power stations in the Middle East. It cost approximately $\$ 170$ million and produces approximately $160 \mathrm{GWh}$ annually, which equals $1 \%$ of the annual energy output in Jordan. Other stations, such as Mafraq, Aqaba, Al-Quwaira, and others, produce roughly 700 megawatts, which produce approximately 700 megawatts, contributing about $8 \%$ of Jordan's energy productivity. Jordan seeks to achieve $20 \%$ of the energy produced through this aspect. Similar to this work, the interaction of other facilities from schools, universities, government departments, factories, and even mosques came to place solar panels and use solar energy to reduce electricity expenditures. On the other hand, wind energy is one of the important resources in Jordan, whose plants generate nearly 190 megawatts, as the third-best Arab country in this regard, also other sources such as oil shale and bioenergy.

\section{Awareness of Green Building}

The most crucial component for starting with a practical plan and achieving the desired results in any aspect is the scientific understanding of consumers and residents. This applies to the concept of sustainable building. Researchers first began to investigate the extent of people's awareness of the concept of green building, as well as its effectiveness and importance for the environment and the environment. Based on a study conducted by Häkkinen and Belloni in 2011, they determined that awareness of green buildings and related concepts is the main factor in the success of this project's progress plan. Manaktola and Jauhari conducted a study on public awareness of green buildings in 2007 (Jauhari and Manaktola, 2007). They found that a good group of people are aware of green buildings and the concept of sustainable building. However, they were not prepared to take this experiment, work on it, and handle some of the costs of developing their buildings to meet green building standards. Eves and Kippes (2010) conducted another study on a segment of the New Zealand population. They found that, despite this portion of society's knowledge of green building concepts, the implemented projects fell short of expectations. This applies to all segments of other societies. As a result, it can be concluded that awareness is a critical aspect in the success of the environmental plan for green buildings.

83 This work is licensed under a Creative Commons Attribution 4.0 International License. 


\section{Awareness in Jordan}

In Jordan, there is a growing awareness of green buildings. The survey results in the recent past revealed a lack of sufficient awareness among the Jordanians of the detailed concepts of green buildings in terms of design, resources, materials, and others. In contrast, $67.1 \%$ of the population surveyed had only an overview of the green building concept, while $32.9 \%$ had practical experience in some green projects (Alawneh et al., 2018). But despite this, it was evident in this segment also the lack of knowledge about aspects of green building, manufacturing, cost, recycling, and others. Some studies also found that major obstacles are standing against green buildings in Jordan, the most important of which is the consumer's view of the project's high cost. Green building strategies are known to be environmentally and economically feasible in the long term, and this is also hidden by the consumer due to the lack of sufficient awareness. This situation has lately improved, particularly with the growth of environmentally friendly projects, but there is still a need to provide greater awareness on the part of universities, the Syndicate of Engineers, the Jordanian Council for Green Buildings, and all those concerned with the matter (Alawneh et al., 2018).

\section{Cost of Green Building}

Concerning building and construction, some professionals and owners argue that sustainable construction is more expensive than traditional construction regarding the materials used and the building protocols. However, when the part that explains the economic engineering value of the green building has been examined, it found that there may be some increased costs, but in the long run, green building excels in all aspects of economic savings. Green building is economically possible in comparison to others because it saves energy, electricity, and health factors. Many studies have focused on the economic aspect of green building (Kats, 2003) elements regarding their long-term economic viability that are difficult to say, such as the effect of green construction on the health of the facility's users. However, the cost varies depending on the abundance of resources and environmental aspects that can be used or must be preserved. (Kats, 2003) conducted a study that combats the argument that green building always costs more. It was found that green building costs only about $2 \%$ more than traditional construction if the project is studied well. He studied 33 sustainable buildings in the United States of America and compared them to traditional buildings in terms of cost, and found that the cost does not exceed 3 dollars per square meter, and this is nothing compared to what was common among people.

\section{Cost of Green Building in Jordan}

Concerning the issue of cost in Jordan, there is no doubt that Jordan is one of the developing countries that used to import all green building materials from abroad, and this was raising the cost of sustainable construction in general. At present, many factories provide all the needs of green building such as insulation materials, environmentally friendly lighting, solar heaters, solar panels, and others (which will be mentioned in detail later in the Methodology section) in addition to the Jordanian government support for all projects that concern the environment and exempt them from taxes. This implemented green building is not that expensive compared to standard construction in Jordan. It even made Jordan one of the leading countries in the field of green buildings. Especially with the presence of engineers and specialists with good experience in this field (Tewfik \& Ali, 2014).

\section{Green Building Benefits}

Many studies have been conducted around the world that gives evidence about the efficiency of green building and how it helps in solving climate problems, creating a healthy environment for societies, and supporting the economic field around the world. 


\section{Environment Benefits}

The term global warming is one of the common concepts in the world that has resulted from bad environmental habits. (Wilson, 2012) The study also shows that green building can reduce negative impacts on the environment, such as global warming by reducing construction waste, reducing consumption of natural materials, recycling materials, and other environmentally friendly strategies. The US Department of Energy has reviewed several LEED-certified green buildings. (Goodstein \& Polasky, n.d.) Energy consumption was reduced by $25 \%$ and water use decreased by $11 \%$.

\section{Economic Benefits}

The economic aspect is one of the priorities that must be taken into account when searching for solutions to a specific problem or when planning a development process for a project. Based on studies and research, the green building project is one of the things that help in developing the global and local economy as well. A study was conducted on a category of green buildings to clarify their economic efficiency. The higher the market values of a facility, the higher the global rating from international rating organizations such as LEED and BREEN.

\section{Social Benefits}

In the recent past, the building was subjected to design and construction under economic, political, and social constraints, resulting in substandard practices that ignored the environmental component and the health of the users. For example, after the global oil crisis, sealed buildings helped minimize the energy necessary for cooling and heating. This is known as Sick Building Syndrome, which in turn affects the economic side of facilities. Green building strategies such as the development of ventilation, lighting and raw materials used have positively affected indoor environmental quality. For example, the LEED global rating system has monitored this aspect and set environmental limits for it.

\section{METHODOLOGY}

Contact was made with specialists in green building in Jordan and with government institutions responsible for this aspect. As the Engineers Association and the Jordanian Council for Green Buildings. Also, some institutions provide green building materials such as solar panels, solar heaters, insulation materials, and others. In this part, a simulation was conducted of a proposed building on which the studied green building materials are applied to find out how effective they are and how to take advantage of them. This section also includes a reallocation of the proposed model that has been designed, input tables for materials used in the design, and sections of the designed model.

\section{Project Flowchart}

Figure 1 depicts a project flowchart, which is divided into several phases. The first step is to analyse and understand the problems. Then the literature and research are studied, which helps in research and investigation about the available green building materials. Sufficient information was then collected about the selected materials and how to apply and use them in a highly efficient manner. In the next stage, a virtual model of a threedimensional building is designed, on which the selected green building materials are applied, such as insulation materials, shading materials, glass facades and sustainable energy sources. The entire environmental setting of the building is done and inputs are provided such as location coordinates, materials used and energy source. This enables us to apply the simulation and obtain accurate modelling results. 
Figure 1: Flowchart of design of sustainable construction green building

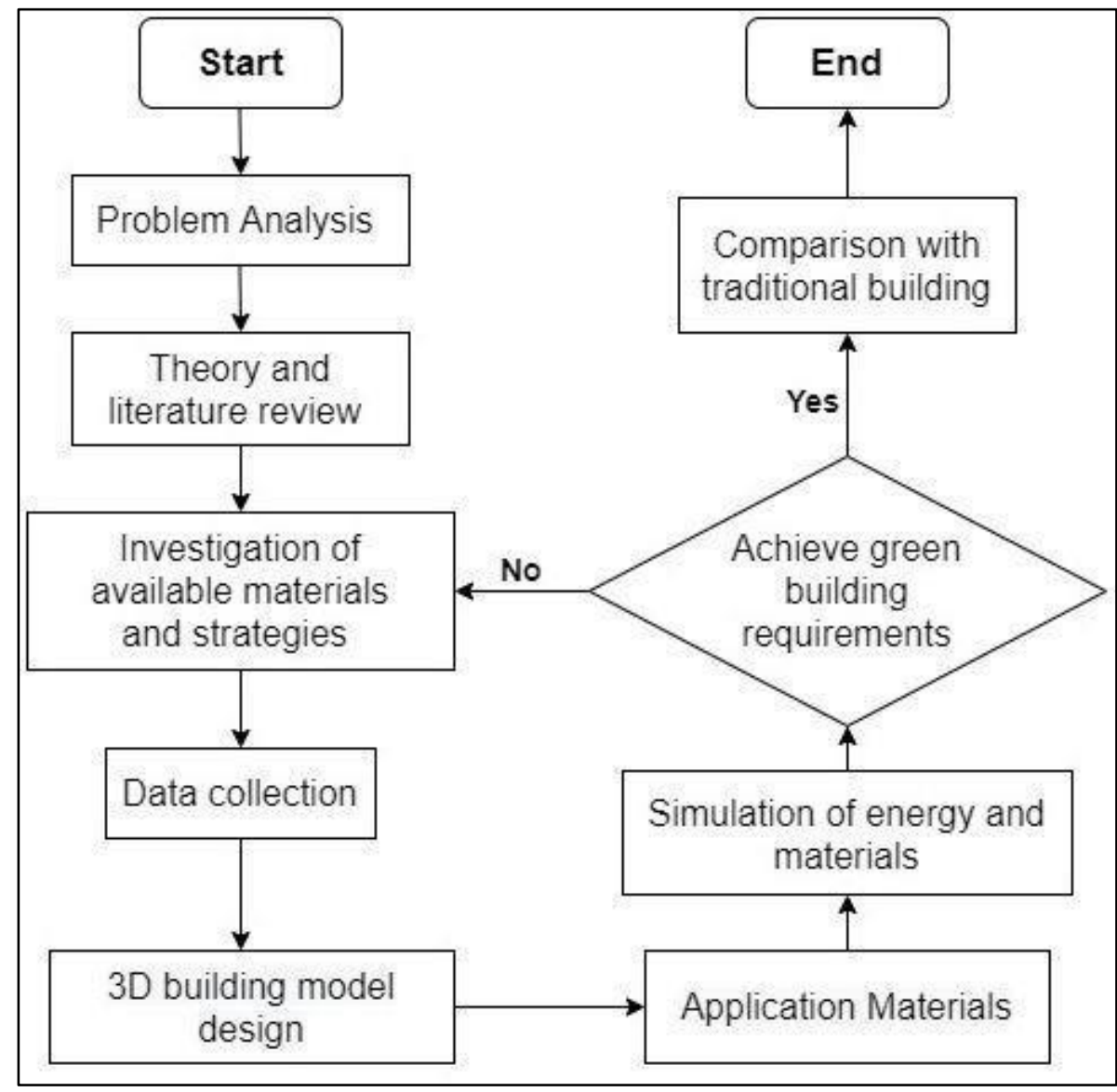

\section{Simulation Tools}

GRAPHISOFT's ARCHICAD is a popular and powerful architectural $\mathrm{CAD}$ and building design and information program used by civil engineers and architects. The software has been proven to be appropriate for a variety of designers, including architects, interior designers, and planners. Enhancement features include CineRender, Parametric Profile Editor, remastered Façade, and BIMx mobile model visualization. ArchiCAD software is a professional building information software solution that satisfies the vast majority of digital delivery requirements. The software offers an intuitive design environment, open collaboration provides accurate building information management and automated documentation.
ArchiCAD, produced by the US business Graphisoft, is one of the two most popular BIM design software and has building SMART IFC certification. The energy diagnosis can be performed using both program-integrated functions and a plug-in: Eco Designer STAR. This latter is an essential component of the software itself. Its calculation engine (StruSoft's VIP-Core) complies with the ASHRAE 140-2007 and ASHRAE 90.12007 (LEED Energy) requirements. As a result, it operates in a dynamic environment. The major innovation of the plug-in is the inclusion of missing tools in the standard tool package (such as a thermal bridge or renewable energy calculation) as well as the option to export files in.gbXML and.PHPP format, allowing for easier collaboration between professionals and technicians (Bonomolo et al., 2021).

86 | This work is licensed under a Creative Commons Attribution 4.0 International License. 


\section{RESULTS AND DISCUSSION}

This section describes the significant outcome of green building modelling. The effect of shading includes both renewable and non-renewable energy sources such as solar energy and oil. This section describes an insulator on a building at the AlZaytoonah University of Jordan in Amman, as well as the ultimate simulated result.

\section{Sun Radiation Study and Daytime Natural Lighting of the Building}

In this result, two designs are considered to understand the effect of shading means on building, the first design comprises the multipurpose modelling hall with tree shading and the other is the modelling of the multipurpose all without tree shading.

The building is depicted in Figure 2 without the use of shading. According to the simulated system and the achieved result, there is a lot of direct sun radiation toward the building, particularly through the building's wall and side roof. Because the building lacks any methods of shade to shield it from direct sunshine, they will have a significant impact during the day because the building will get hotter than usual, causing the HVAC system, such as the air conditioning system, to work unnecessarily and consume more electricity.

Figure 3 represents the building with shading means using trees in order to achieve green building, based on the simulated system and achieved result, there is no direct sun radiation toward the building, especially through the wall and side roof of the building, especially through the wall and side roof of the application of the tree shading devices denote an efficient passive method of solar radiation or heat control, in the shaded area of the entire building, the thermal load and irradiative will significantly lower when compared to Figure 2 with building with nonshaded ones. Therefore, the trees through their cooling effect lower the amount of air temperature around the building and also help the HVAC system inside the building which includes the air condition system to work at normal or less electricity consumption. However, the result also indicated that, during the day, there would be brightness, and based on the modelling of the building, the brightness will reflect into the building which will aid natural daytime lighting and help to save energy, increase health and comfort the level for the multipurpose hall occupant during an event.

\section{Figure 2: Building Without trees shading means}

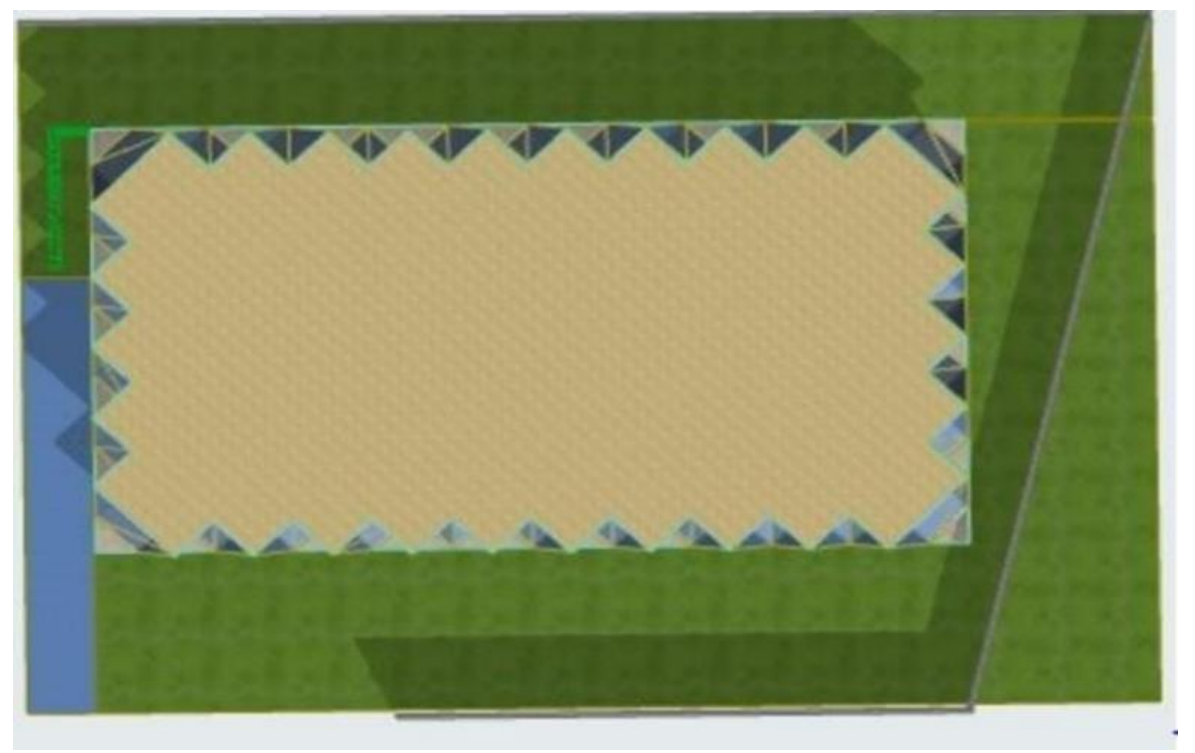

87 | This work is licensed under a Creative Commons Attribution 4.0 International License. 
Figure 3: Building with trees shading means

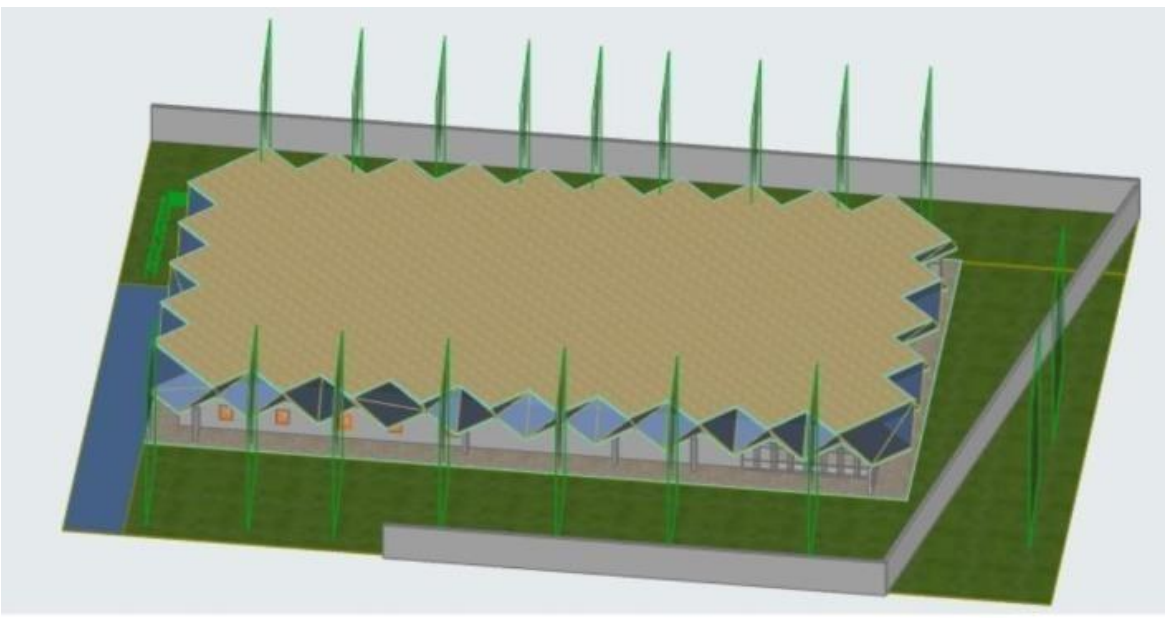

\section{Energy Performance Study}

The energy performance study result toward the modelled green building is discussed in this result. This outcome is critical for gaining access to sustainable building modelling. As a result, there are primarily two sorts of key sources of electricity production for the building. The first is a building that is normally powered by $100 \%$ solar panels, while the second is powered by $50 \%$ solar energy and $50 \%$ oil-based power generator.

\section{Key-Value of the Building}

The end outcome is the building's main asset. This comprises the building's location as well as the climatic data source from the trustworthy server. Based on the building modelling, it also provides the geometry and heat coefficient of the building. However, there are two sorts of outcomes analyses for energy performance studies, as shown in Figures 4 and 5. According to Figure 4, this energy performance research based on the main value of the building is for the building model with 100 per cent solar panel, with a total energy of $6.16 \mathrm{kWh} / \mathrm{m} 2$ a. It also has a fuel cost of $2.44 \mathrm{GBP} / \mathrm{m} 2 \mathrm{a}$. However, as a building model to achieve a sustainable construction green building, the use of solar panels achieved Zero $\mathrm{CO} 2$ emission, making the building model green with low energy consumption approaches. According to Figure 5, this is the evaluation of the building modelling based on $50 \%$ solar energy, $50 \%$ oil-based power generator in comparison to building modelling based on $100 \%$ solar panel, the result achieved similar energy consumptions because all load applications for the building remained the same, however, the utilization of $50 \%$ oil-based power generator makes the building to have $5.58 \mathrm{~kg} / \mathrm{m} 2$ a CO 2 emission.

This section describes the simulation of how the building energy is balance. This varies by week. The building is simulated based on expected and estimated energy without considering daylight natural lighting. Otherwise, it takes into account the predicted energy usage and performance of artificial lighting and equipment during day and night use. The results showed that there is a projected 91794.4 KW/a of lighting and equipment energy balancing in a year with a heat gain of $484533 \mathrm{KWh} / \mathrm{a}$, as well as the building energy balance for ventilation transfer, human heat gain, infiltration, and transmission. To summarize this part of the study, it is noted that lighting energy can reduce with natural daylight lighting. 
East African Journal of Engineering, Volume 3, Issue 1, 2021

Article DOI: https://doi.org/10.37284/eaje.3.1.410

Figure 4: Building with $100 \%$ solar energy input source

\section{Thermal Block - Key Values}

\begin{tabular}{|c|c|c|c|c|c|}
\hline \multicolumn{3}{|l|}{ Geometry Data } & \multirow{2}{*}{$\begin{array}{l}\text { Heat Transfer Coefficients } \\
\text { Floors: }\end{array}$} & $U$ value & \multirow[t]{2}{*}{$\mathrm{W} / \mathrm{m}^{2} \mathrm{~K}$} \\
\hline Gross Floor Area: & 2899.33 & $\mathrm{~m}^{2}$ & & - & \\
\hline Treated Floor Area: & 2893.17 & $\mathrm{~m}^{2}$ & External: & $3.51-3.51$ & \\
\hline Building Shell Area: & 67.88 & $m^{2}$ & Underground: & - & \\
\hline Ventilated Volume: & 10704.72 & $\mathrm{~m}^{3}$ & Openings: & - & \\
\hline Glazing Ratio: & 0 & $\%$ & Annual Supplies & & \\
\hline Internal Temperature & & & Heating: & 0.00 & kWh \\
\hline Min. (04:00 Mar. 18): & 2.86 & ${ }^{\circ} \mathrm{C}$ & Cooling: & 17835.93 & kWh \\
\hline Annual Mean: & 21.65 & ${ }^{\circ} \mathrm{C}$ & & & \\
\hline \multirow[t]{2}{*}{ Max. (12:00 Jul. 26): } & 47.57 & ${ }^{\circ} \mathrm{C}$ & Peak Loads & & \\
\hline & & & Heating (01:00 Jan. 01): & 0.00 & kW \\
\hline Unmet Load Hours & & & Cooling (08:00 Mar. 23): & 10.00 & $\mathrm{~kW}$ \\
\hline Heating: & 1017 & hrs/a & & & \\
\hline Cooling: & 1616 & hrs/a & & & \\
\hline
\end{tabular}

Figure 5: Build with 50\% solar energy and 50\% oil input source

\begin{tabular}{|c|c|c|c|c|c|}
\hline \multicolumn{6}{|l|}{ Key Values } \\
\hline General Project Data & \multirow{3}{*}{\multicolumn{2}{|c|}{ multipurpose hallsim4 }} & Heat Transfer Coefficients & $\mathrm{U}$ value & {$\left[\mathrm{W} / \mathrm{m}^{2} \mathrm{~K}\right]$} \\
\hline Project Name: & & & Building Shell Average: & 3.51 & [ \\
\hline City Location: & & & Floors: & - & \\
\hline Latitude: & \multicolumn{2}{|c|}{$32^{\circ} 0^{\prime} 49^{\prime \prime} \mathrm{N}$} & External: & $3.51-3.51$ & \\
\hline Longitude: & \multicolumn{2}{|c|}{$35^{\circ} 52^{\prime} 28^{\prime \prime} \mathrm{E}$} & Underground: & _- & \\
\hline Altitude: & \multicolumn{2}{|c|}{$0.00 \quad \mathrm{~m}$} & Openings: & -- & \\
\hline Climate Data Source: & \multicolumn{5}{|c|}{ Strusoft server } \\
\hline \multirow[t]{2}{*}{ Evaluation Date: } & \multirow{2}{*}{\multicolumn{2}{|c|}{ 6/30/2021 12:02 AM }} & Specific Annual Values & & \\
\hline & & & Net Heating Energy: & 0.00 & $\mathrm{kWh} / \mathrm{m}^{2} \mathrm{a}$ \\
\hline \multicolumn{3}{|l|}{ Building Geometry Data } & Net Cooling Energy: & 6.16 & $\mathrm{kWh} / \mathrm{m}^{2} \mathrm{a}$ \\
\hline Gross Floor Area: & 2899.33 & $m^{2}$ & Total Net Energy: & 6.16 & $\mathrm{kWh} / \mathrm{m}^{2} \mathrm{a}$ \\
\hline Treated Floor Area: & 2893.17 & $m^{2}$ & Energy Consumption: & 37.89 & $\mathrm{kWh} / \mathrm{m}^{2} \mathrm{a}$ \\
\hline External Envelope Area: & 67.88 & $\mathrm{~m}^{2}$ & Fuel Consumption: & 33.85 & $\mathrm{kWh} / \mathrm{m}^{2} \mathrm{a}$ \\
\hline Ventilated Volume: & 10704.72 & $\mathrm{~m}^{3}$ & Primary Energy: & 109.85 & $\mathrm{kWh} / \mathrm{m}^{2} \mathrm{a}$ \\
\hline \multirow[t]{2}{*}{ Glazing Ratio: } & \multirow[t]{2}{*}{0} & \multirow[t]{2}{*}{$\%$} & Fuel Cost: & 2.44 & $\mathrm{GBP} / \mathrm{m}^{2} \mathrm{a}$ \\
\hline & & & $\mathrm{CO}_{2}$ Emission: & 5.59 & $\mathrm{~kg} / \mathrm{m}^{2} \mathrm{a}$ \\
\hline \multicolumn{6}{|c|}{ Building Shell Performance Data } \\
\hline \multirow[t]{3}{*}{ Infiltration at $50 \mathrm{~Pa}:$} & \multirow[t]{3}{*}{0.03} & \multirow[t]{3}{*}{$\mathrm{ACH}$} & Degree Days & & \\
\hline & & & Heating (HDD): & 1760.22 & \\
\hline & & & Cooling (CDD): & 3063.87 & \\
\hline
\end{tabular}

\section{Project Energy Balance}

The project Energy Balance consisted of a thorough assessment of the main techniques connected to the analysis of electricity usage in terms of lighting and equipment, ventilation, and cooling. This also covers human heat gain and adds latent energy, human heat gain, and infiltration, all of which are examined as $\mathrm{kWh}$ per annum for 52 weeks. The analysis comprises an estimate of the proposed and constructed building's equipment and lighting. This also includes infiltration, which is the process by which water on the ground's surface enters the soil and is estimated to be $35 \mathrm{KWh} / \mathrm{a}$.

In terms of latent or human heat gain, this is a sensible and latent heat that is emitted with an internal space from any source and is removed by ventilation or air conditioning in an increase in humidity and temperature within space, resulting in estimated energy consumption or utilization of $107577.8 \mathrm{KWh} / \mathrm{a}$ for the modelled green building while adding latent heat energy results. This section also describes the simulation of how the building energy is balanced, which varies by week; the building is simulated based on expected and estimated energy without taking into account daylight natural lighting; otherwise, it takes into account the expected artificial lighting and equipment energy usage and performance when used during the day and night. The findings indicated that a year's worth of lighting and equipment energy balance is projected to be

89 This work is licensed under a Creative Commons Attribution 4.0 International License. 
91794.4 KW/a, with a heat gain of $484533 \mathrm{KWh} / \mathrm{a}$. The outcome also indicates the energy balance of the building for ventilation, transmission, human heat gain, infiltration, and transmission. In order to conclude this part of the result, it is observed that the lighting energy can decrease with daylight natural lighting.

\section{Figure 6: Building energy balance}

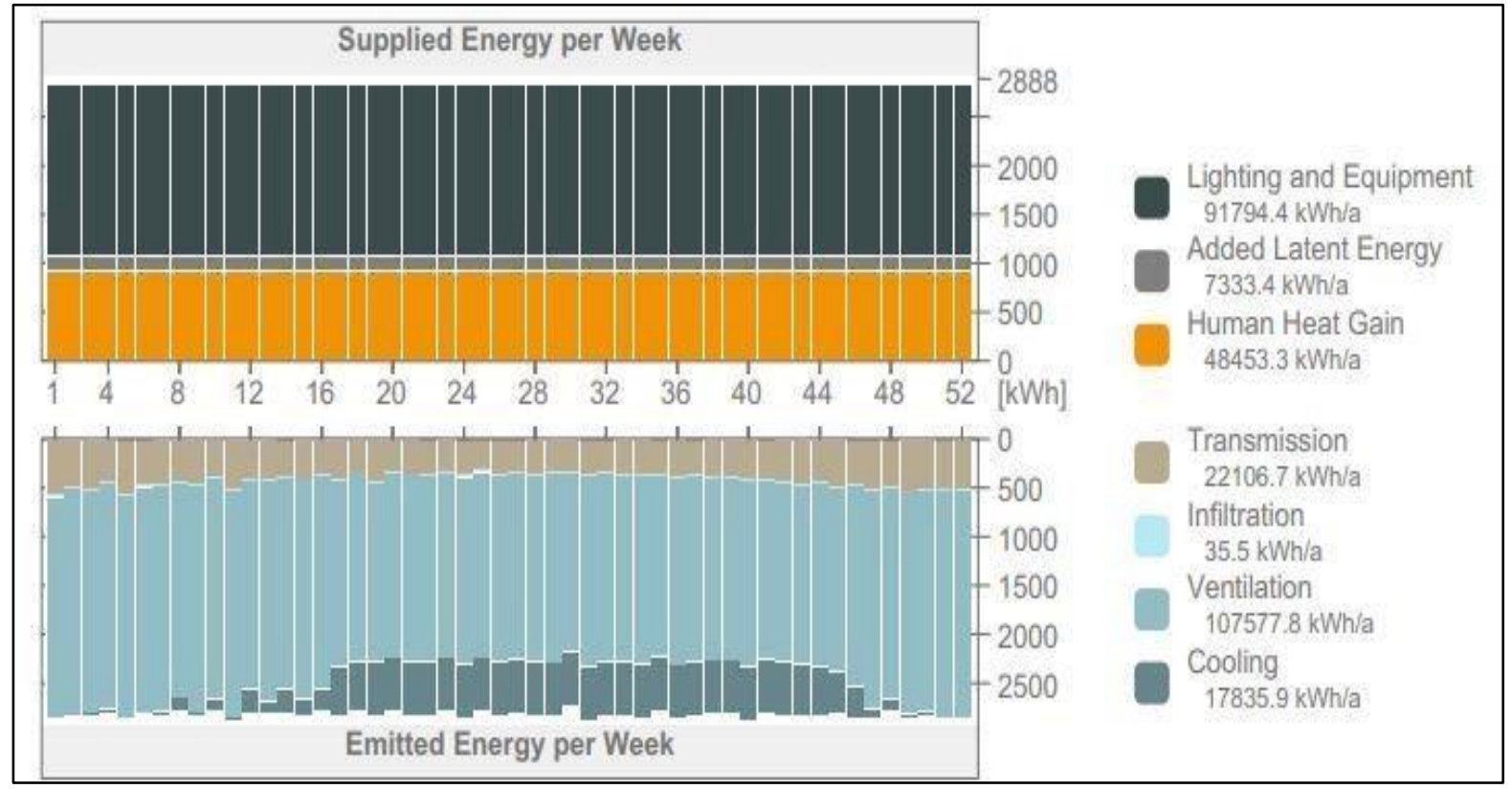

\section{Energy Consumption by Target}

The project which considers oil or fossil fuel and renewable energy such as solar energy for the building required proper evaluation to understand the building sustainability when comparing the building having $50 \%$ fossil fuel with $50 \%$ as a source of energy or $100 \%$ solar power as a source of energy; therefore energy consumption by the target is a significant analysis to understand the overall emissions, in this result, the target is main the cooling and lighting and appliance in the building while the source of energy is electricity supplied either through $50 \%$ fossil fuel with $50 \%$ or $100 \%$ solar power. However, this analysis facilitates energy utilization to account for the use of renewable energy supply sources or oil-based energy supply sources. The goal is to estimate the usage and reduction in energy demand and also to assess the emission of energy in terms of clean or carbon, the final analysis could facilitate the benefit of the green building when compared with buildings powered by fossil fuel.

Based on the target energy such as the cooling and lighting and appliance, the result provides the quantity of this energy usage per year. It also includes the cost, the amount of $\mathrm{CO} 2$ emission, the result achieved for the energy consumption of the building divided by the target such as cooling and ventilation fan, according to figure 7 , due to the utilization of $100 \%$ solar energy for power production, the result estimated zero $\mathrm{CO} 2$ emission with a cost of 442 GDP/a and 6609 GDP/a for cooling and ventilation fan respectively. However, in figure 8 , the result projected $1014 \mathrm{~kg} / \mathrm{a}$ and 15146 $\mathrm{kg} / \mathrm{s} \mathrm{CO} 2$ emissions for cooling and ventilation fan respectively with a cost of 442 GDP/a and 6609 GDP/a for cooling and ventilation fan respectively owing to the use of 50\% Solar Energy and 50\% Oil Input Source for power production.

90 | This work is licensed under a Creative Commons Attribution 4.0 International License. 
East African Journal of Engineering, Volume 3, Issue 1, 2021

Article DOI: https://doi.org/10.37284/eaje.3.1.410

Figure 7: Energy Consumption by Target (Build with 100\% Solar Energy Input Source)

\begin{tabular}{|c|c|c|c|c|}
\hline \multicolumn{4}{|c|}{ Energy } & \multirow{3}{*}{$\begin{array}{c}\mathrm{CO}_{2} \\
\text { Emission } \\
\mathrm{kg} / \mathrm{a}\end{array}$} \\
\hline Target Name & Quantity & Primary & Cost & \\
\hline & MWha & MWh/a & GBP/a & \\
\hline Heating & 0 & 0 & 0 & 0 \\
\hline Cooling & 17 & 42 & 442 & 0 \\
\hline Service Hot-Water & 0 & 0 & 0 & 0 \\
\hline Ventilation Fans & 0 & 0 & 0 & 0 \\
\hline Lighting \& Appliances & 91 & 275 & 6609 & 0 \\
\hline Total: & 109 & 317 & 7052 & 0 \\
\hline
\end{tabular}

Figure 8: Energy Consumption by Target (Build with 50\% Solar Energy and 50\% Oil Input Source)

\begin{tabular}{|c|c|c|c|c|c|c|}
\hline \multicolumn{6}{|c|}{ Energy } & \multirow{2}{*}{$\begin{array}{c}\mathrm{CO}_{2} \\
\text { Emission } \\
\mathrm{kg} / \mathrm{a}\end{array}$} \\
\hline \multicolumn{3}{|c|}{ Target Name } & Quantity & Primary & Cost & \\
\hline Heating & & & 0 & 0 & 0 & 0 \\
\hline Cooling & & & 17 & 42 & 442 & 1014 \\
\hline Service Hot- $\mathrm{Y}$ & Vater & & 0 & 0 & 0 & 0 \\
\hline Ventilation Fa & & & 0 & 0 & 0 & 0 \\
\hline Lighting \& Ap & pliances & & 91 & 275 & 6609 & 15146 \\
\hline Total: & & & 109 & 317 & 7052 & 16160 \\
\hline $\mathrm{CO}_{2}:$ & $6 \%$ & \multicolumn{4}{|c|}{$93 \%$} & \\
\hline \multirow{2}{*}{\multicolumn{7}{|c|}{$\begin{array}{l}\text { Energy Target: } \\
\text { Energy Source: }\end{array}$}} \\
\hline & & & & & & \\
\hline \multicolumn{2}{|c|}{$\mathrm{kg} / \mathrm{a} 1014.8$} & \multicolumn{3}{|c|}{15146.1} & & \\
\hline 0 & & 5000 & & 10000 & & 16160 \\
\hline
\end{tabular}

\section{Thermal Insulation}

Simulation of temperature difference from outside to the wall side of the building simulated in order to test the effect of temperature difference inside the building based on selected insulator, according to the simulated result in Figure 9, the result indicated that, as the temperature hit the wall of the building, the temperature energy dissipated noticed the red colour turning to blue colour making the inside of the building to cool during the day.

91 This work is licensed under a Creative Commons Attribution 4.0 International License. 
Figure 9: Thermal insulation simulation result

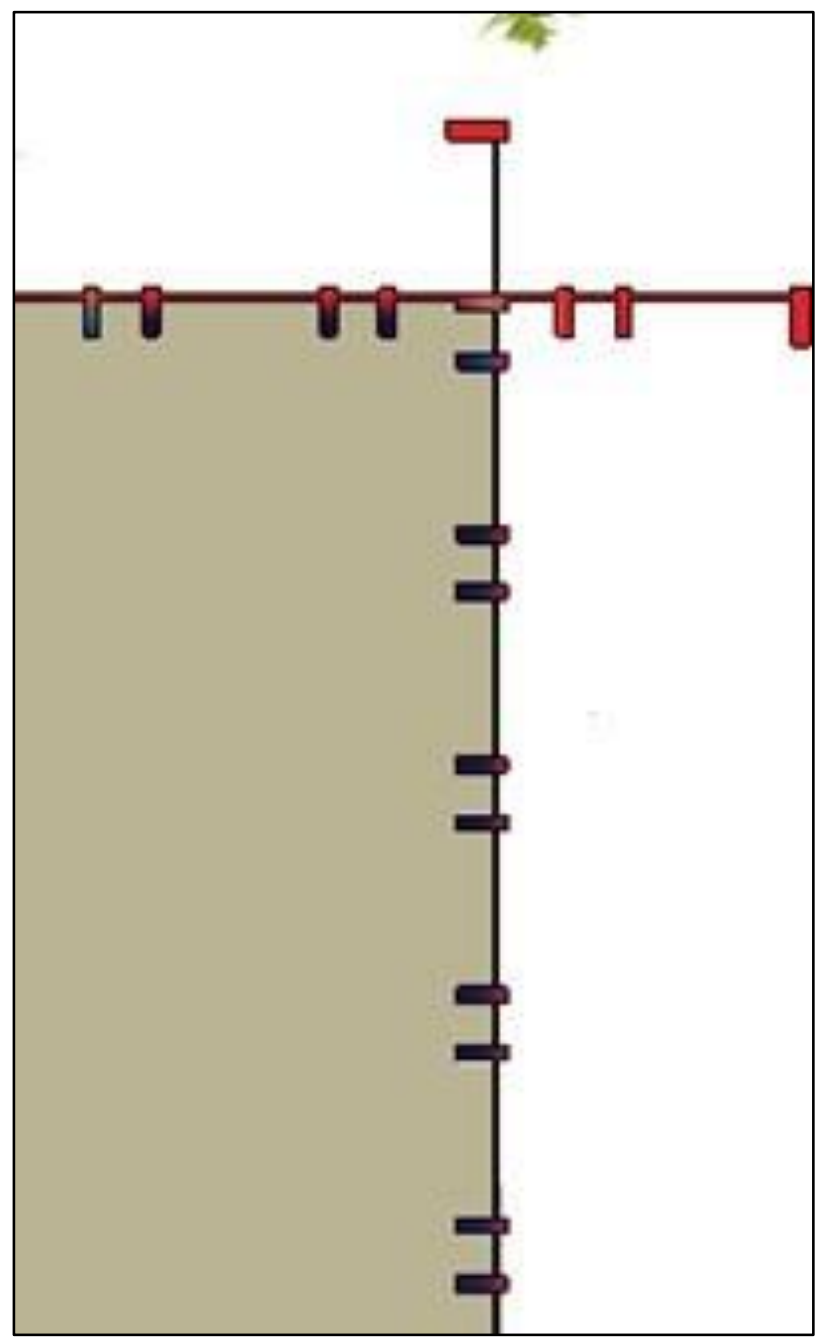

Figure 10: Thermal Bridge Simulation

(2) Thermal Bridge Simulation

Show Results for:

fi: Temperature

Ed Energy flow

ra

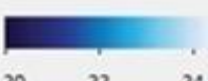

$\left[W / m^{2} \mathrm{k}\right.$

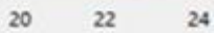

26

Psi-value:

Number of iterations:

Relative unbalance:

Asymmetry index

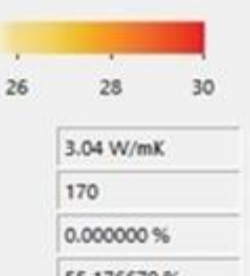

$55.176679 \%$

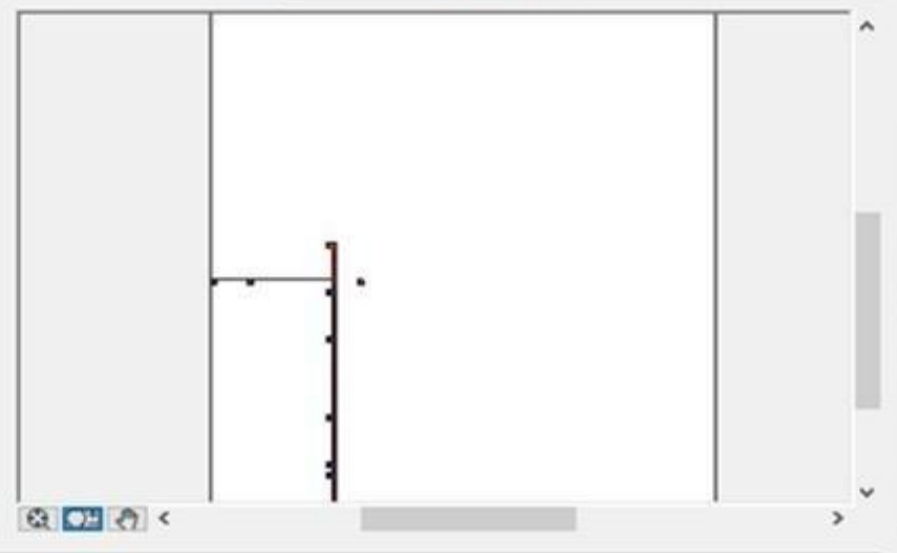

92 This work is licensed under a Creative Commons Attribution 4.0 International License. 
In Figure 10, this Psi value was obtained as the result of the simulation done on the building using insulation materials. The inputs here are (internal heat, external heat, thermal conductivity etc.), Where the program provides the calculations based on the mathematical equations related to each parameter.

\section{Environmental Impact}

Table 1: Environmental impact of the modelling
This section presents the environmental impact of the system modelling; based on the final result, it can be concluded that building power with oil will have a negative impact on the environment in terms of $\mathrm{CO} 2$ emission; thus, a building with 100 per cent solar energy input source has zero $\mathrm{CO} 2$ emission and is considered a green building, while a building with $50 \%$ solar energy and $5 \%$ oil has a negative impact on the environment in terms of $\mathrm{CO} 2$ emission.

\section{Source Name Building with 100\% Solar EnergyBuilding with 50\% Solar Energy and 50\% Oil Input Source (CO2 Input Source (CO2 emission kg/a) emission kg/a)}

\begin{tabular}{lll}
\hline External Air & 0 & 0 \\
Electricity & 0 & 16160 \\
Total & 0 & 16160 \\
\hline
\end{tabular}

\section{Software Mechanism}

When performing energy and material performance assessments using ArchiCAD's built-in tools, input data such as building location, building type, power source, insulators used and many more should be included. In order to ensure a high level of accuracy in the results.

Inputs must be determined before the energy assessment is performed. For example, in this paper, the power source and the exact construction site have been updated. Because based on the location, the minimum, maximum, and average outside temperature of the location are automatically determined based on online climate data. Before starting the analysis, three types of information are provided for the program (Geometrical/structure, energy sources, and environmental information).

All calculations are based on the three data mentioned, for example, for arithmetic operations. The program calculates the thermal insulators and the U-value and R-value as follows: The materials that comprise the provided structure are listed in the U-value calculator, together with their relevant properties (thickness, thermal conductivity, density, and heat capacity), each of which shows a default value.

Note: These values are derived from the Physical Properties panel of the Building Materials dialog in ArchiCAD. Which is based on globally recognized values of material specifications. Any of these values can be edited manually.

As shown in Figure 11, the external and internal heat transfer coefficients, as well as the thermal bridge effect associated with the structural surface area, are shown at the bottom left of the U-Value (RValue) Calculator dialog. This data, as well as material properties, are necessary for the calculation. The calculated $U$ value is displayed in the lower right corner of the panel. 


\section{Figure 11: U-Value Calculator}

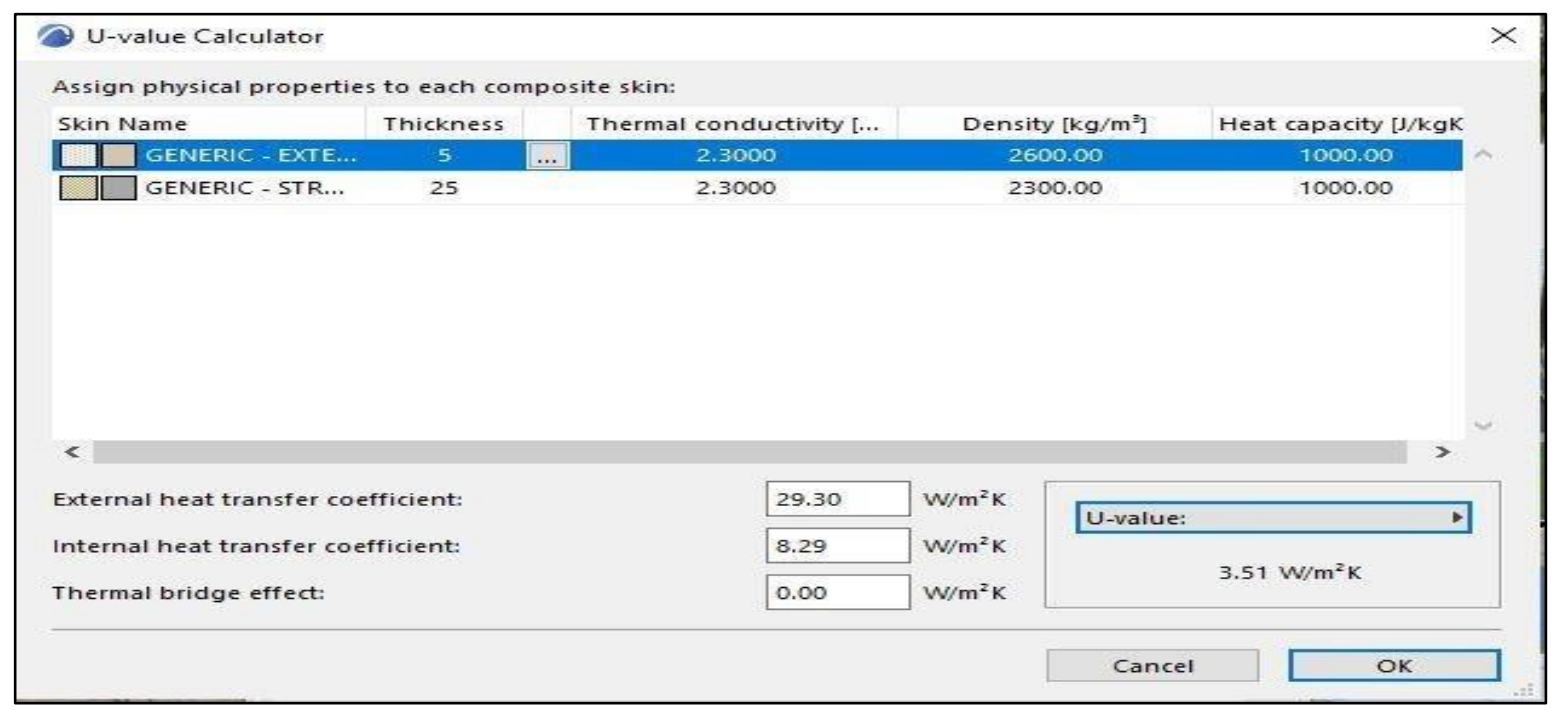

The calculated $\mathrm{U}$ value shown in the figure dialog box is based on the performance data of the fixed building component. This type of data is listed under the core values/heat transfer coefficients in the Energy Performance Assessment Report. However, the energy assessment uses a more accurate dynamic computation algorithm to calculate the hourly heat transfer through building envelope structures when simulating the building's energy balance for the reference year. The result of this dynamic analysis is the basis for the energy consumption, carbon emissions, and monthly energy balance data presented in the Energy Assessment Report.

\section{U-value (R-value) Calculation Algorithm}

Based on a stationary algorithm utilized by most national standards, the U-value Calculator computes the average heat transmission coefficient of Building Materials and composite constructions.

\section{Figure 12: U-Value Equation}

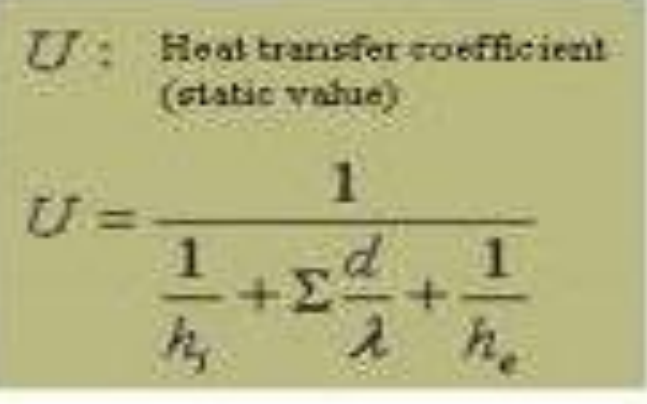

$h_{3}:$ intemel bost tranafer coefficient

h. : External ziest transfer coefficient

$d:$ man thichess

2: themnal ecoidietmity
Delta U-values are added to the average U-values of structural group entries to account for the impacts of thermal bridges. The magnitudes of the exterior and internal heat transfer coefficients, as well as the delta U-value, are affected by the analysed structure's position concerning the thermal current. Default settings are available within Energy Evaluation. However, it is recommended to check

94 | This work is licensed under a Creative Commons Attribution 4.0 International License. 
and manually override these predetermined values if the structural situation requires it or if the project location's standards differ. Look through the skins given in the U-value calculator. While the fill type, name, and thickness of each skin are determined by the element settings in ArchiCAD, as shown in
Figure 13, you can change the three properties to the right of the vertical line - Thermal conductivity, density, and Heat capacity - if the default values here do not correspond to your actual project structures.

\section{Figure 13: Physical Property Assignment}

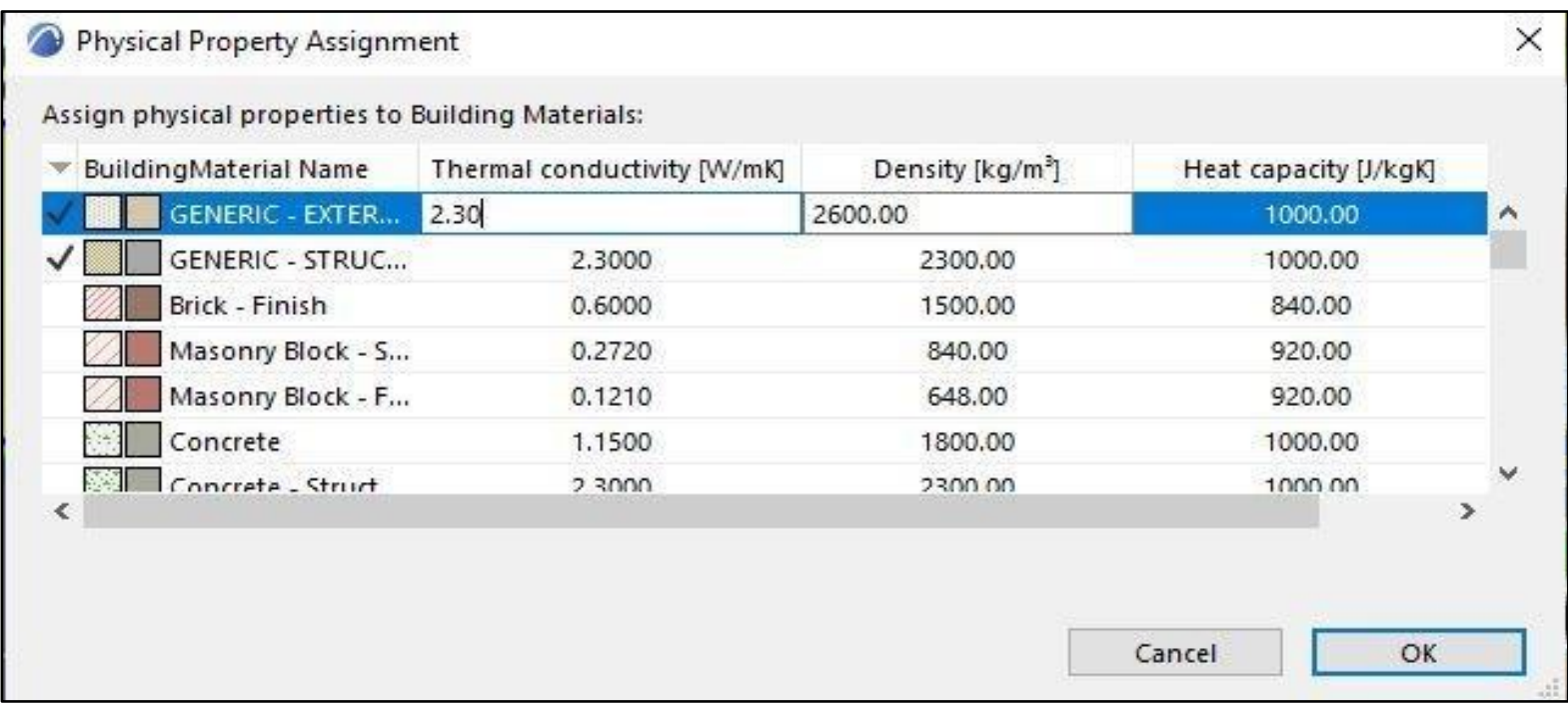

\section{Summary}

The result generated from the modelling of the green building, the effect of shading means with trees, renewable and non-renewable energy such as solar energy and oil, insulator on building located at Al-Zaytoonah University of Jordan in Amman described in this section along with the final simulated result, this result consider daytime natural lighting and the effect of shading means on building by doing sun radiation study, energy performance study result toward the modelled green building was also discussed based on building with $100 \%$ solar panel and building with 50\% solar energy and 50\% oil-based power generator, the work also simulated the effect of temperature differences inside the building based on selected insulator, and the final result indicated that building power with oil will have a negative impact to the environment in terms of $\mathrm{CO} 2$ emission, therefore, the building with $100 \%$ solar energy input source has zero $\mathrm{CO} 2$ emission and is considered as green building, while building with 50\% solar energy and 50\% oil input source emitted high amount of $\mathrm{CO} 2$ to the environment.

\section{CONCLUSION}

The research has been carried out based on the problem statement and to achieve the objectives that were set. The research is divided into different sections based on the objectives. The first part of the project is to search for strategies and materials available in Jordan that can be applied to construction to benefit from natural energy sources and reduce the negative impact on the environment. Some green building materials were identified and applied to a proposed building model located in a university in Jordan.

First, thermal insulation materials were applied to the roof, ceiling and walls. Thermal insulation materials showed their effectiveness in maintaining the internal building temperature and their ability to 
control the R-value of the building. This was clearly demonstrated in the transformation of the colour from red on the surface of the outer walls to blue colour on the inner surface of the walls due to the insulation used. Here, the first goal of the research was achieved.

In order to achieve the second goal, which represents the means of shading. The model in which the shading was used showed that it avoided direct sunlight, which greatly affects the operation of the HVAC system, which includes HVAC and ventilation. Shading thus helps reduce the energy loads required to maintain the building's internal temperature. Unlike the model that did not use shading, which will require high energy to cool the building during the day, especially in the summer.

Finally, to achieve the latter goal, a comparison was conducted of a proposed building in which $100 \%$ solar energy was used. On the other, it has been used $50 \%$ solar energy and $50 \%$ oil energy. The results showed that a building that uses $100 \%$ solar energy produces zero $\mathrm{CO} 2$ value. Thus, it achieves the concept of green building. At the same time, a building that uses $50 \%$ of oil energy and $50 \%$ of solar energy produces $\mathrm{CO} 2$ emissions at high rates. This shows the negative environmental impact of this model.

\section{Recommendations}

The green building was created to achieve the aims and handle the issues associated with the problem statement; nevertheless, there are other requirements that the work will recommend having immediate and future actions for strengthening the project during implementation; thus, it is recommended by the designers to considers all the project material investigation appropriately and start by selecting those materials find suited for the project construction, also the impact of the project on the environment has been analysis but the scope is limited to $\mathrm{CO} 2$, it is recommended that other environmental impact should be analysis are determine the minimum environmental impact for the construction, the work also recommends further simulation in terms of thermal analysis, solar gradient analysis, elevation analysis and the impact of people in the building towards the sustainable green building proposed and developed need to analysis with appropriate simulation software. It is also recommended to carry out a proper evaluation on the renewable energy technology and how they are incorporated into the building; the final recommendation is to change the usage of some materials such as transparent glass into a reusable or easy recycled type of material.

\section{REFERENCES}

Alawneh, R., Ghazali, F. E. M., Ali, H., \& Asif, M. (2018). Assessing the contribution of water and energy efficiency in green buildings to achieve United Nations Sustainable Development Goals in Jordan. Building and Environment, 146, 119132.

Alshorman, A. A., Talat, N. T., Alshorman, M., \& Alrawashdeh, K. A. B. (2018). Jordanian green building approach for energy efficiency improvement. Int. J. Eng. Technol., 7(4), 30433047.

Bhutta, F. M. (2017, November). Application of smart energy technologies in building sectorfuture prospects. In 2017 International Conference on Energy Conservation and Efficiency (ICECE) (pp. 7-10). IEEE.

Bonomolo, M., Di Lisi, S., \& Leone, G. (2021). Building Information Modelling and Energy Simulation for Architecture Design. Applied Sciences, 11(5), 2252.

Cedeño-Laurent, J. G., Williams, A., MacNaughton, P., Cao, X., Eitland, E., Spengler, J., \& Allen, J. (2018). Building evidence for health: green buildings, current science, and future challenges. Annual review of public health, 39, 291-308. 
Goodstein, E. S., \& Polasky, S. (2017). Economics and the Environment. John Wiley \& Sons.

Dar-Mousa, R. N., \& Makhamreh, Z. (2019). Analysis of the pattern of energy consumptions and its impact on urban environmental sustainability in Jordan: Amman City as a case study. Energy, Sustainability and Society, 9(1), 15

Eves, C., \& Kippes, S. (2010). Public awareness of "green" and "energy efficient" residential property: An empirical survey based on data from New Zealand. Property Management.

Gibberd, J. (2002, May). The sustainable building assessment tool assessing how buildings can support sustainability in developing countries. In Built Environment Professions Convention (pp. 1-3).

Gissen, D. (2010). Territory: architecture beyond environment. Architectural Design, 3(80), 8-13.

Häkkinen, T., \& Belloni, K. (2011). Barriers and drivers for sustainable building. Building Research \& Information, 39(3), 239-255.

Hassouneh, K., Al-Salaymeh, A., \& Qoussous, J. (2015). Energy audit, an approach to apply the concept of green building for a building in Jordan. Sustainable Cities and Society, 14, 456462.

Houser, T. (2009). Energy Efficiency in Buildings: A Global Economic Perspective (No. PB09-8). Peterson Institute for International Economics.

Kaatz, E., Root, D. S., Bowen, P. A., \& Hill, R. C. (2006). Advancing key outcomes of sustainability building assessment. Building Research \& Information, 34(4), 308-320.

Kats, G. H. (2003). Green Building Costs and Financial Benefits. Massachusetts Technology Collaborative. Westborough, MA: Renewable Energy Trust.
Kibert, C. J. (2016). Sustainable construction: green building design and delivery. John Wiley $\&$ Sons.

Lu, Y., Cui, P., \& Li, D. (2018). Which activities contribute most to building energy consumption in China? A hybrid LMDI decomposition analysis from year 2007 to 2015. Energy and Buildings, 165, 259-269.

Manaktola, K., \& Jauhari, V. (2007). Exploring consumer attitude and behaviour towards green practices in the lodging industry in India. International journal of contemporary hospitality management.

Martinez, J., Mboup, G., Sliuzas, R., \& Stein, A. (2008). Trends in urban and slum indicators across developing world cities, 19902003. Habitat International, 32(1), 86-108.

Matarneh, R. T. (2017). Development of sustainable assessment method and design tool for existing and traditional buildings in Jordan. Architecture Civil Engineering Environment, 10(4), 15-31.

Millán, J. D. R., Rupp, R., Mueller-Putz, G., Murray-Smith, R., Giugliemma, C., Tangermann, M., ... \& Mattia, D. (2010). Combining brain-computer interfaces and assistive technologies: state-of-the-art and challenges. Frontiers in neuroscience, 4, 161.

Samy, M. M., \& Barakat, S. (2019, December). Hybrid invasive weed optimization-particle swarm optimization algorithm for biomass/PV micro-grid power system. In $201921 s t$ International Middle East Power Systems Conference (MEPCON) (pp. 377-382). IEEE.

Tewfik, M., \& Ali, M. M. (2014). Public green buildings in Jordan. Eur. Int. J. Sci. Technol, 3, 284-300.

Tripathy, B. C., Esi, A., \& Tripathy, B. (2005). On new types of generalized difference Cesaro

97 | This work is licensed under a Creative Commons Attribution 4.0 International License. 
East African Journal of Engineering, Volume 3, Issue 1, 2021

Article DOI: https://doi.org/10.37284/eaje.3.1.410

sequence spaces. Soochow Journal of

Mathematics, 31(3), 333.

World Commission on Environment and Development (WCED). (1987). World commission on environment and development. Our common future. Geneva: WCED.

Wilson, G. (2012). Community resilience and environmental transitions. Routledge.

98 This work is licensed under a Creative Commons Attribution 4.0 International License. 